\title{
On the Influence of Surface Hardening Treatments on Microstructure Evolution and Residual Stress in Microalloyed Medium Carbon Steel
}

\author{
Andreas Fischer, Berthold Scholtes, and Thomas Niendorf
}

\author{
(Submitted January 14, 2020; in revised form April 7, 2020)
}

\begin{abstract}
Tailoring surface properties is a key to superior performance of components subjected to fatigue loadings in application. Process-microstructure-property relationships have to be established to allow for optimization of techniques employed for surface treatments such as deep rolling and induction hardening. Although both techniques are employed widely in industrial application, studies examining microstructure evolution and residual stress states for a single material in a comparative manner are missing. Amongst others, this is related to the labor-intensive characterization techniques to be employed for this purpose. In order to establish pathways toward more efficient characterization approaches, the present work evaluates relations between microstructure evolution, hardness and results obtained by x-ray diffraction for a medium carbon steel treated by established surface hardening techniques. In this context, a strong correlation between hardness values and integral width distributions obtained by $x$-ray diffraction can be seen, while only weak correlations between hardness and residual stress measurements are existing. For in-depth microstructure analysis, high-resolution electron optical microscopy has proven to be very effective in resolving microstructural features down to the nanoscale substantiating elementary relationships. The study focuses on highly stressed fillet regions of real components, i.e., crankshaft sections. A 44MnSiVS6 microalloyed steel grade was used for measurements, representing a current standard for the crankshaft production in the automotive sector.
\end{abstract}

Keywords characterization, hardness, residual stress, surface, steel, $x$-ray diffraction analysis

\section{Introduction}

A preliminary performance prediction is one of the main objectives of automotive designers (Ref 1). For critical components in the automotive industry, several surface treatments are used to increase the resistance to fatigue loadings, corrosion and wear. Moreover, numerous automotive design requirements in terms of material choice, thermal and mechanical treatments, manufacturing processes and cost-efficiency for high-performance components have to be critically considered in parallel (Ref 2-4). Especially the crankshaft is one of the main components of an engine being highly stressed. In order to cover application oriented needs, different surface hardening treatments such as deep rolling (mechanical treatment) and induction hardening (thermal treatment) exist, all aiming at the reduction of wear and extension of the in-service life of the crankshaft (Ref 5-8).

The process of deep rolling leads to local plastic deformation within the surface and subsurface area by applying a specific pressure by means of a controlled ball or roller. Besides

Andreas Fischer, Berthold Scholtes, and Thomas Niendorf, Institute of Materials Engineering - Metallic Materials, University of Kassel, Mönchebergstraße 3, 34125 Kassel, Germany. Contact e-mail: a.fischer@uni-kassel.de.

the resulting compressive residual stress state, strain hardening and diminished surface roughness positively influence damage tolerance (Ref 7). Induction surface hardening is performed by a rapid inductive heating of a selected part of the component, which is then shortly kept for austenitization, followed by rapid quenching (Ref 8). Through this treatment, a tough core featuring tensile residual stresses and a hard surface layer with compressive residual stresses can be established, hampering fatigue crack initiation and growth in the hardened surface layer (Ref 6).

Deep rolling and induction hardening are commonly established surface hardening treatments, already numerously used in the automotive industry for treatment of crankshafts in order to induce compressive residual stresses as well as to affect local hardness distribution of the material employed (Ref 1,9). In fact, the material behavior, the component geometry as well as the parameters used for deep rolling and for induction hardening, respectively, directly control the residual stress distribution (Ref 6, 10,11). However, the effectiveness of the induced residual stresses depends largely on their distribution in the treated surface area and on their resistance to relaxation during subsequent fatigue loading. As a consequence of the aforementioned aspects, crack initiation in direct vicinity of the surface or below the hardened layer can occur. Due to this reason, the optimization of the residual stress profile for a given component and material, respectively, is of utmost importance for superior damage tolerance (Ref 6, 12).

The main objective of the present paper is to evaluate possible correlations between the hardness distribution and values obtained by x-ray diffraction analysis (residual stress and integral width) for one distinct component treated by established surface hardening techniques. Investigations are 
carried out on crankshaft sections made from medium carbon 44MnSiVS6 microalloyed steel. Since fatigue crack initiation in such kind of component mainly occurs in direct vicinity of the fillet region, characterization is only focused on this specific area. Investigations cover the initial material state for reference, the deep rolled condition and the induction hardened condition. Results imply that the residual stress distribution is strongly influenced by changes in microstructure. Hardness and x-ray diffraction measurements are complemented by electron optical microscopy. For this purpose, in-depth analysis using electron backscatter diffraction (EBSD) and electron channeling contrast imaging (ECCI) was conducted. Both techniques are used for detailed characterization of local microstructural features and crystal defects imposed by the differing hardening techniques employed. In fact, EBSD and ECCI are able to provide for a better understanding of relations between hardness and results obtained by x-ray diffraction measurements.

\section{Experimental Procedures}

\subsection{Material Conditions and Surface Hardening Parameters}

Investigations focused on individual crankshaft sections. A microalloyed 44MnSiVS6 steel was used, being a common steel grade for automotive components (Ref 3). Information on time-temperature-transformation (TTT) curves for a similar steel is provided in (Ref 13). Standard processing routes as employed for parts in serial production were used. Steel was supplied by Sidenor (Bilbao, Spain). Crankshafts were manufactured by forging. Detailed parameters for manufacturing and heat treatments, respectively, are intellectual property (IP) of the respective companies and, thus, cannot be provided. The chemical composition of the final crankshaft sections as determined by spark spectroscopy is given in Table 1 .

The crankshafts were characterized in three different conditions: the initial condition for reference, a deep rolled condition and an induction hardened condition. All crankshafts were forged and subsequently machined (the condition being termed initial condition), ensuring an adequate basis for all subsequent hardening treatments. In this regard, deep rolled and induction hardened crankshaft segments constitute the conditions being in focus of the present work.

Deep rolling was conducted by Hegenscheidt, Germany. The process parameters for deep rolling at room temperature comprised a force of $55 \mathrm{kN}$, a ball size radius of $3.4 \mathrm{~mm}$ and a rolling angle of $34.85^{\circ}$, resulting in a rolling force of $33.5 \mathrm{kN}$. Each rolling cycle was carried out with a total of 13 runs. The complete deep rolling cycle comprised five times overrolling beginning with a contact force of $0.3 \mathrm{kN}$ followed by a linear increase up to the maximum force of $33.5 \mathrm{kN}$, five times overrolling with maximum force and three times overrolling with linear decreasing force down to a contact force of $0.3 \mathrm{kN}$. Active material cooling was not necessary due to the very localized load impact and the slow speed, so that the occurrence of high temperatures could be ruled out.

The induction hardening process was carried out by Comforsa with an induction power of $80 \mathrm{~kW}$. The corresponding holding times during austenitization as well as quenching rates are IP of Comforsa and, thus, cannot be provided. The subsequent quenching process was accomplished using a quenching fluid consisting of water and $10 \%$ Aquaquench $^{\circledR}$ (polymer). The temperature of the quenching bath was $30^{\circ} \mathrm{C}$.

\subsection{Cutting of Crankshaft Sections}

Figure 1 schematically highlights the processing steps conducted for preparation of the final crankshaft sections (used for characterization). Figure 1(c) shows the final geometry obtained by conventional sawing (with intermediate steps shown in Fig. 1a and b). The final sample geometry used for hardness testing, XRD characterization and microscopy can be seen in Fig. 1(e) obtained by wire-cut electro-discharge machining (EDM) alongside the broken line as superimposed to Fig. 1(d). In this context, wire-cut EDM was employed in order to prevent a significant rearrangement of the residual stress distribution in the vicinity of the fillet area (Ref 14). Industrial practice employs similar sample preparation procedures for quality assurance (Ref 15,16$)$.

\subsection{Measurement Parameters and Associated Sample Preparation}

In the following techniques employed for further sample preparation as well as the testing conditions for hardness measurements according to Vickers, characterization of the residual stress distribution and the integral width distribution, the analysis of microstructure and the parameters used for EBSD and ECCI are detailed. In order to analyze a potential correlation between the hardness profile and the values obtained by $\mathrm{x}$-ray diffraction measurements, it was necessary to carry out the corresponding measurements on the same sample and within the same area for each material state. The area of interest (AoI) for the crankshaft analyzed is highlighted in Fig. 2(a) by the black circle.

In order to ensure comparability between the hardness profile and the results of the $\mathrm{x}$-ray diffraction measurements always the same measuring procedure had to be employed. For this reason, five directions were defined. Alongside each direction, the methods detailed above were employed (Fig. 2b). The number of measured points needed for each angle

Table 1 Chemical composition of 44MnSiVS6 (1.5233) in wt. \%

\begin{tabular}{|c|c|c|c|c|c|c|c|}
\hline C & $\mathbf{S i}$ & Mn & $\mathbf{P}$ & $\mathbf{S}$ & $\mathrm{Cr}$ & Mo & $\mathbf{N i}$ \\
\hline 0.44 & 0.78 & 1.23 & 0.02 & 0.04 & 0.09 & 0.01 & 0.07 \\
\hline $\mathrm{Cu}$ & Al & Ti & & $\mathbf{N b}$ & $\mathbf{V}$ & $\mathbf{W}$ & Co \\
\hline 0.08 & 0.01 & 0.01 & & $<0.01$ & 0.26 & 0.03 & 0.01 \\
\hline
\end{tabular}



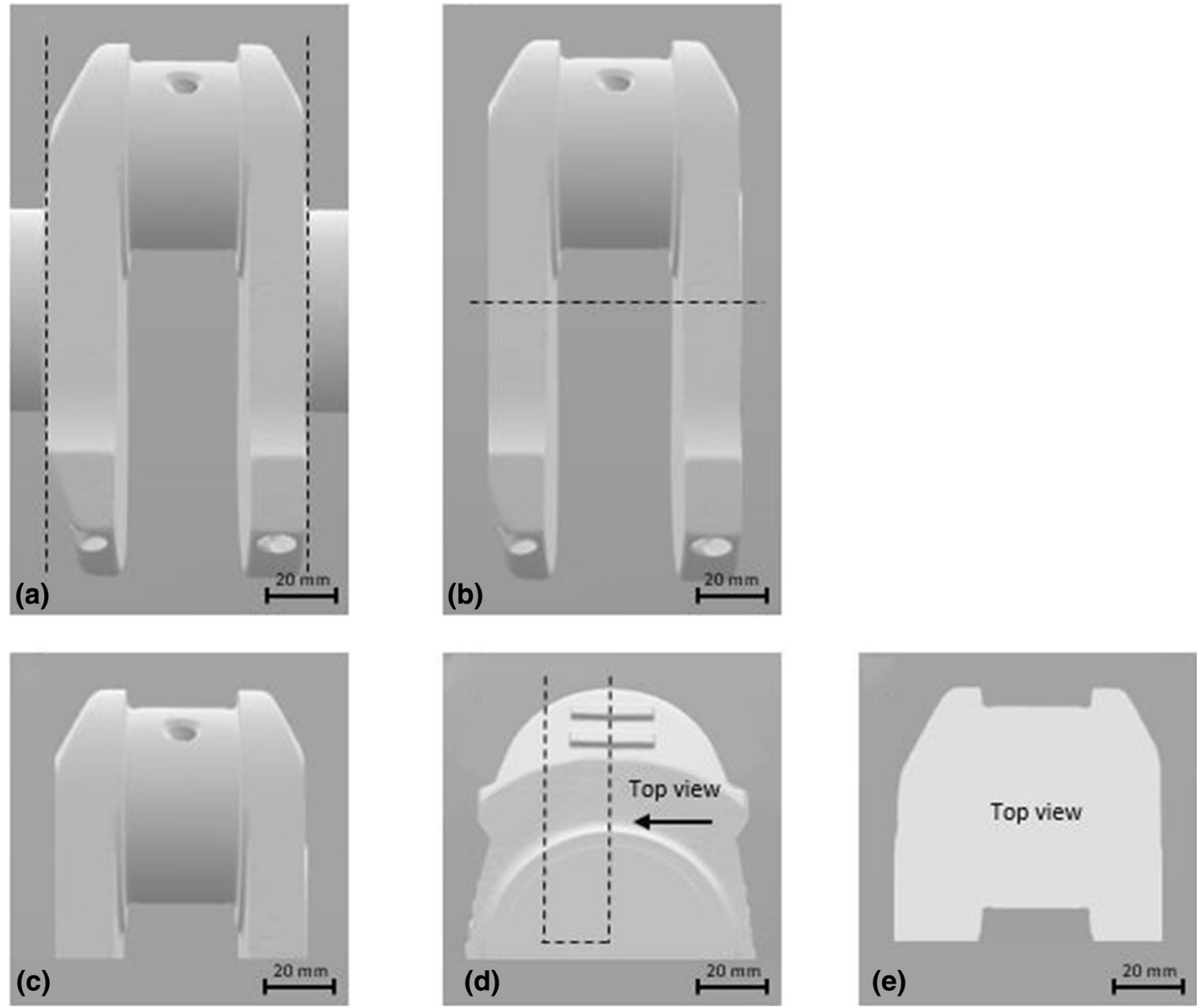

Fig. 1 Cutting out crankshaft sections: (a), (b), (c) sawing; (d), (e) wire-cutting
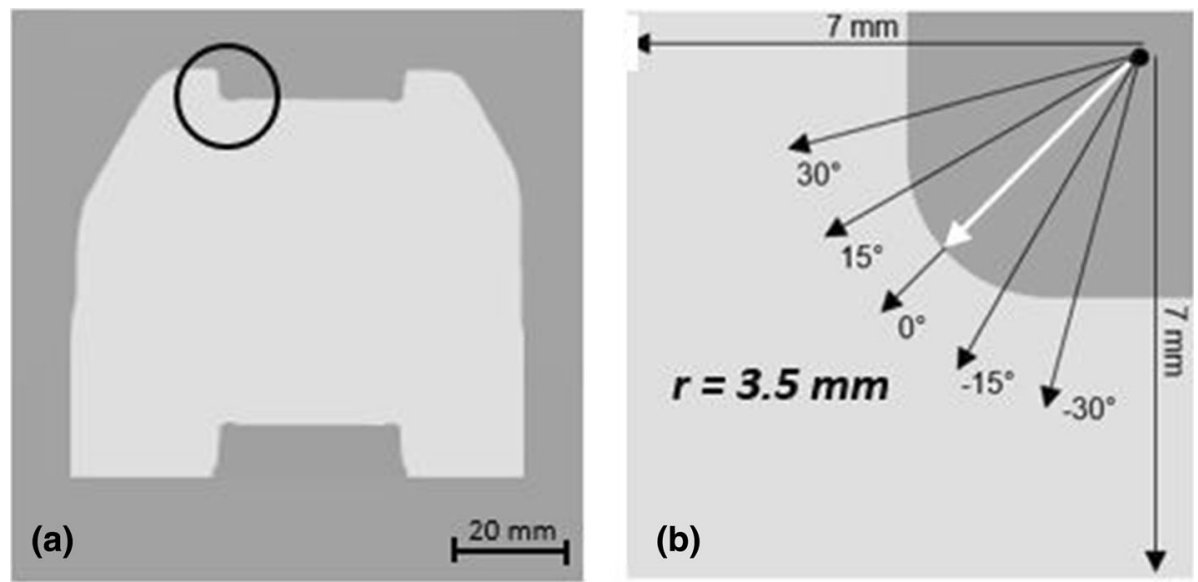

Fig. 2 (a) AoI for all samples (black circle), (b) detailed view on the AoI, including respective dimensions and defined directions

displayed depended on the in-depth effect of the individual surface hardening treatment. Furthermore, EBSD and ECCI characterization was carried out in the AoI defined in Fig. 2(a).

2.3.1 Hardness Measurements. For hardness testing, samples were ground and polished. The hardness measurements according to Vickers HV 0.5 (testing load of $4.903 \mathrm{~N}$ ) were carried out using a Struers DuraScan 70 system. Refer- ring to the corresponding standard, the distance between single indents and the distance from the edge was set to $0.25 \mathrm{~mm}$ (Ref 17). In addition to the hardness measurements alongside the displayed angles (Fig. 2b) for each material condition, a fullfield hardness measurement was conducted for the induction hardened condition to obtain more information from the fillet region. Considering the crankshaft fillet radius of $3.5 \mathrm{~mm}$, an 
area of $7 \mathrm{~mm} \times 7 \mathrm{~mm}$ was defined as AoI for hardness mapping (indicated in Fig. 2b). Average hardness values provided in the results section were calculated based on all data stemming from this AoI.

2.3.2 X-ray Diffraction Measurements. X-ray diffraction measurements were performed using a diffractometer D 5000 equipped with a $\mathrm{Cr}$ source. The diffractometer was operated at $35 \mathrm{kV}$ and $30 \mathrm{~mA}$. For the x-ray diffraction measurements, a monocapillary of $0.3 \mathrm{~mm}$ in diameter was used. The diffracted intensity was measured on the basis of the (211) plane of the ferrite from $148^{\circ}$ to $164^{\circ}$ using a step size of $0.1^{\circ}$ and a counting time of $2 \mathrm{~s}$. For stress evaluation, the classical $\sin ^{2}-\Psi$ method was applied, using $11 \Psi$ angles (Ref 18). Furthermore, a distance of $0.25 \mathrm{~mm}$ between the measuring points was defined. The measuring field is highlighted in Fig. 2(b) and exactly follows the procedure described for the hardness measurements. The number of measuring points needed in each case was dependent on the material condition as already detailed above. Due to the potential influence of wirecut EDM (Sect. 2.2) on residual stress distribution within the fillet area of the crankshaft sections, surfaces were electropolished to a depth of $150 \mu \mathrm{m}$. As apt polishing parameters for the material were chosen based on experience, the technique does not induce new residual stresses. Still, minor relaxation and redistribution of the initial residual stress profile caused by removed material (Ref 19) has to be considered. According to the literature, however, corrections with regard to the removed layer are negligible in some cases, especially when stresses are not used for further fatigue performance calculations (Ref 4, 20). For this reason, no corrections were done.

2.3.3 Optical Microscopy. For optical microscopy, all specimens were polished, etched and characterized using a Zeiss Axioplan microscope. The microalloyed 44MnSiVS6 steel grade samples were etched with diluted copper disulfate (ethanol-based solution) for $3 \mathrm{~s}$ in each case. Results were used to screen the overall microstructure evolution within the fillet regions of the differently treated crankshaft sections.

2.3.4 High-Resolution Electron Optical Microscopy (EBSD and ECCI Measurements). EBSD analysis was carried out using a ZEISS Ultra Plus scanning electron microscope (SEM) equipped with a field emission gun operating at an acceleration voltage of $20 \mathrm{kV}$ and high beam current. EBSD measurements were performed using a Bruker eFlash $^{\mathrm{HR}}$ detector with a maximum resolution of $1600 \times 1200$ pixel. To reduce measuring time, a binning mode $(160 \times 120$ pixel $)$ was used. Measurements were conducted with an inclination of the detector of about $3.9^{\circ}$, an inclination of the sample holder of $70^{\circ}$ and at a working distance of $16.5 \mathrm{~mm}$. The step size was set to $0.2 \mu \mathrm{m}$ for the coarsegrained microstructure in the initial and the deep rolled condition, whereas a step size of $0.1 \mu \mathrm{m}$ was chosen for the induction hardened condition due to its very fine-grained microstructure.

Due to geometric constraints imposed by the SEM used, the fillet region had to be cut out by sawing and wire-cut EDM (cf. Figure 2a). Subsequently, EBSD and ECCI specimens were prepared by grinding, polishing and additional vibratory polishing using a colloidal silica solution of $0.04 \mu \mathrm{m}$ for approximately $48 \mathrm{~h}$. As highlighted in Fig. 2(a) (and the respective Results section, Fig. 10) scans were conducted in the edge of the fillet region. For post-processing, TSL OIM 7 Analysis $7 \times 64$ was applied for data analysis, i.e., analysis of texture and local orientation distribution, respectively. A clean-up level of 3 was applied by using a filter of the type "neighbor orientation correlation." The confidence index was set to 0.6. For the different material conditions, inverse pole figure (IPF) maps and kernel average misorientation (KAM) maps were calculated. The IPF maps were colored according to the standard triangle (Ref 21) as shown in respective figures. The local misorientation was analyzed indepth by calculation of the KAM. The average misorientation between a pixel $\mathrm{i}$ and its first neighbor was analyzed in order to obtain detailed information on the orientation differences within single grains. For calculation, a threshold of $<5^{\circ}$ was defined, avoiding any misinterpretation due to the presence of low-angle grain boundaries. Following this procedure, the KAM allows for a quantitative analysis of local plastic strain gradients (Ref 22, 23).

ECCI investigations were conducted using the same ZEISS Ultra Plus SEM at an acceleration voltage of $30 \mathrm{kV}$ and high beam current. ECCI is able to provide for microstructure related contrasts as the intensity of backscattered electrons is strongly dependent on the orientation of the incident beam relative to the crystal planes. Thereby, a modulation of the backscattered electron intensity is caused by slight local distortions in the crystal lattice due to dislocations (Ref 23, 24). Due to differences in the backscattered electron yield in strained regions of a crystal, arising contrasts allow the imaging of near-surface crystal defects (Ref 25, 26).

\section{Results}

\subsection{Hardness, X-ray Diffraction and Micrograph Analysis (Initial Condition of 44MnSivS6)*}

In Fig. 3(a), the hardness distribution of a 44MnSiVS6 crankshaft section in the initial state is shown. As mentioned in Sect. 2.3, the hardness profile was recorded along five angles down to a depth of $2.5 \mathrm{~mm}$. As depicted below, the hardness level remains on a constant level over the whole fillet region. The average hardness is $312 \mathrm{HV} 0.5$. Figure 3(b) and (c) depict the results of the $\mathrm{x}$-ray diffraction measurements. According to Fig. 3(b), the whole fillet region is characterized by a compressive residual stress state. Residual stress values as well as the transition zone are characterized by pronounced scatter along the five angles at relatively low absolute compressive values (not exceeding - $135 \mathrm{MPa}$ ). In Fig. 3(c), the course of the integral width values is displayed. The average integral width of the initial state is $1.9^{\circ}$.

In Table 2, the main results from the hardness and the x-ray diffraction measurements are summarized. The residual stress values near the surface as well as the maximum residual stresses differ for the five angles, however, always are on a very low level (not exceeding - $135 \mathrm{MPa}$ ). In contrast to these results, the integral width and the hardness values remain almost on the same level.

In Fig. 4, the microstructure of a 44MnSiVS6 crankshaft section in the initial state is shown. The optical micrographs indicate the edge layer (a) and the core area (b) of the fillet

\footnotetext{
*Data presented and discussed in Sects. 3.1 to 3.3 are taken from deliverable D.1.2 "Report on characteristics of surface hardened layers produced by IH and DR" being part of a research action funded by RFCS (see "Acknowledgements" for details).
} 

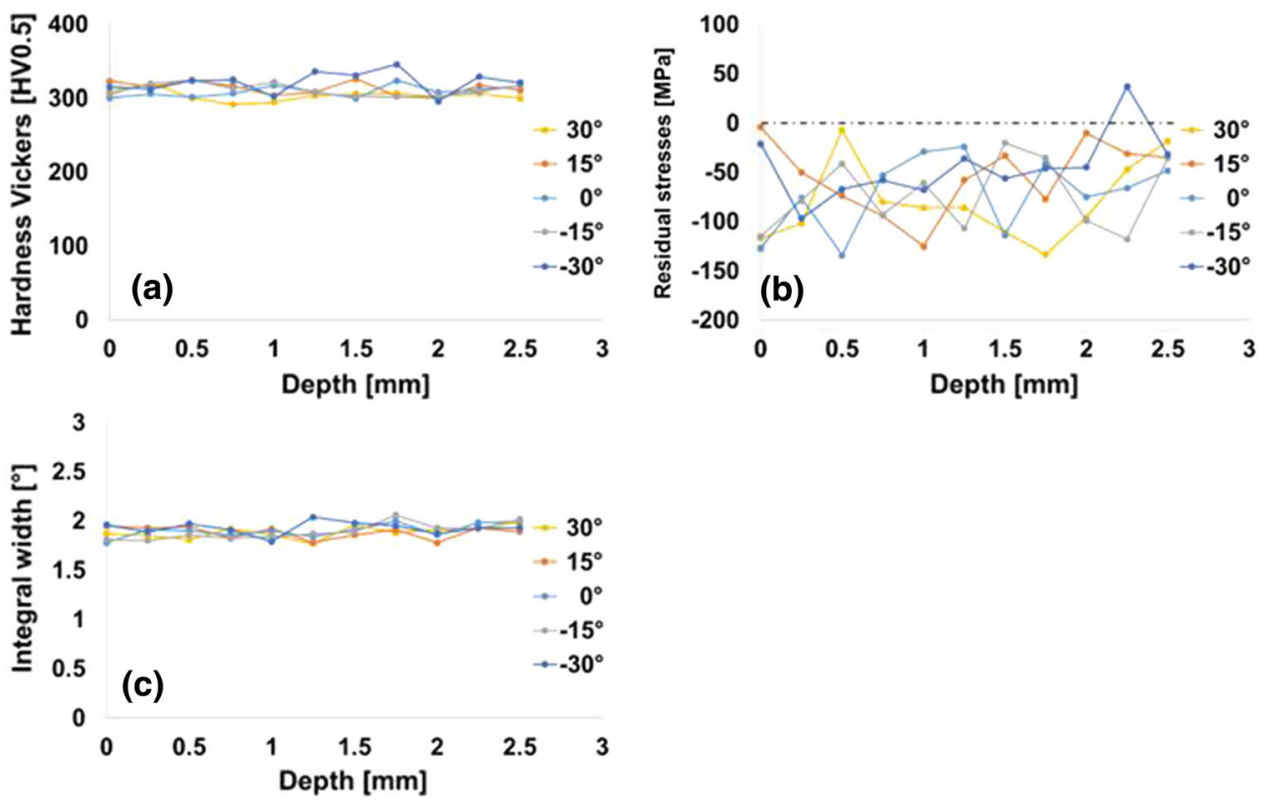

Fig. $344 \mathrm{MnSiVS6}$ in its initial condition: (a) hardness distribution, (b) residual stress distribution, (c) integral width distribution (Color figure online)

Table 2 Quantitative results obtained from the hardness and the x-ray diffraction measurements (initial condition of 44MnSiVS6)

\begin{tabular}{lcccc}
\hline Angle, $^{\circ}$ & Residual stress near the surface, MPa & Max. compr. residual stress, MPa & Max. integral width, ${ }^{\circ}$ & Max. Hardness, HV \\
\hline 30 & -21 & -68 & 1.98 & 320 \\
15 & -4 & -125 & 2 & 326 \\
0 & -127 & -134 & 2.06 & 324 \\
-15 & -115 & -118 & 2.05 & 325 \\
-30 & -117 & -133 & \\
\hline
\end{tabular}
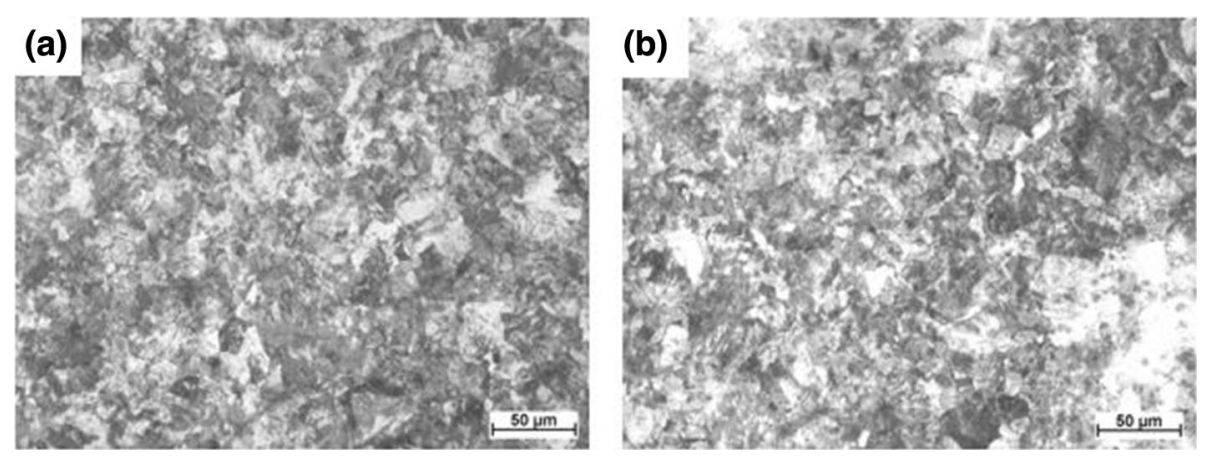

Fig. 4 Optical micrographs displaying the microstructure after etching for 44MnSiVS6 in its initial condition (500-times magnification): (a) edge layer, (b) core

region. In both cases, the figures show a primarily coarsegrained microstructure composed of ferritic-perlitic grains.

\subsection{Hardness, X-ray Diffraction and Microstructure Analysis (Deep Rolled Condition of 44MnSiVS6)}

Figure 5(a) depicts the course of the hardness values for a deep rolled 44MnSiVS6 crankshaft section in the fillet region along the five defined angles. A pronounced increase in hardness values near the surface is seen; below values steadily decrease approximately down to the hardness level of the initial state (mean average of $335 \mathrm{HV} 0.5$ in the deep rolled condition). Figure 5(b) and (c) depict the results of the X-ray diffraction measurements. It is clearly demonstrated that deep rolling induced a new residual stress state being characterized by significantly higher compressive residual stresses near the edge and surface, respectively. Due to the parameters applied for the deep rolling process, the compressive residual stresses reach their maximum level at a depth of 0.5 to $0.75 \mathrm{~mm}$. The zero crossing for all angles ranges from 1.6 to $3.3 \mathrm{~mm}$. In Fig. 5(c), the course of the integral width is displayed. The 

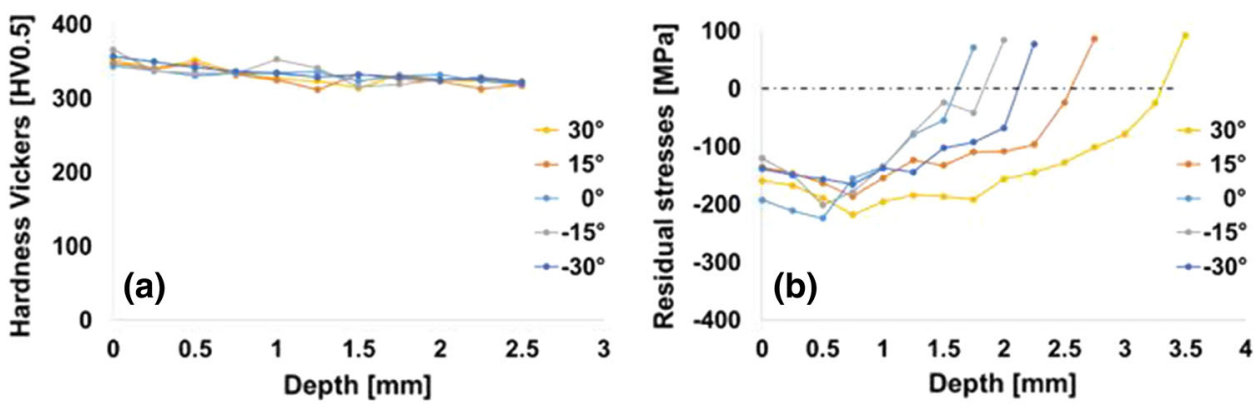

3

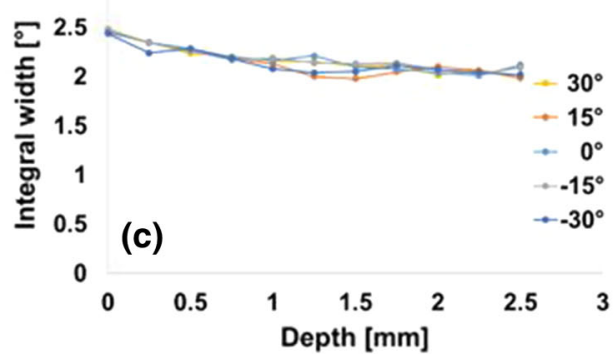

Fig. 5 44MnSiVS6 in its deep rolled condition: (a) hardness distribution, (b) residual stress distribution, (c) integral width distribution (Color figure online)

Table 3 Quantitative results obtained from the hardness and the x-ray diffraction measurements (deep rolled condition of 44MnSiVS6)

\begin{tabular}{|c|c|c|c|c|c|}
\hline Angle, & $\begin{array}{c}\text { Residual stress near the } \\
\text { surface, } \mathrm{MPa}\end{array}$ & $\begin{array}{l}\text { Max. compr. residual } \\
\text { stress, MPa }\end{array}$ & $\begin{array}{l}\text { Zero crossing of residual stress } \\
\text { (transition zone), } \mathrm{mm}\end{array}$ & $\begin{array}{l}\text { Max. integral } \\
\text { width, }{ }^{\circ}\end{array}$ & $\begin{array}{l}\text { Max. } \\
\text { hardness, HV }\end{array}$ \\
\hline 30 & -159 & -218 & 3.3 & 2.48 & 352 \\
\hline 15 & -135 & -186 & 2.55 & 2.45 & 348 \\
\hline 0 & -192 & -224 & 1.6 & 2.49 & 344 \\
\hline-15 & -120 & -201 & 1.8 & 2.48 & 366 \\
\hline-30 & -138 & -165 & 2.1 & 2.44 & 357 \\
\hline
\end{tabular}
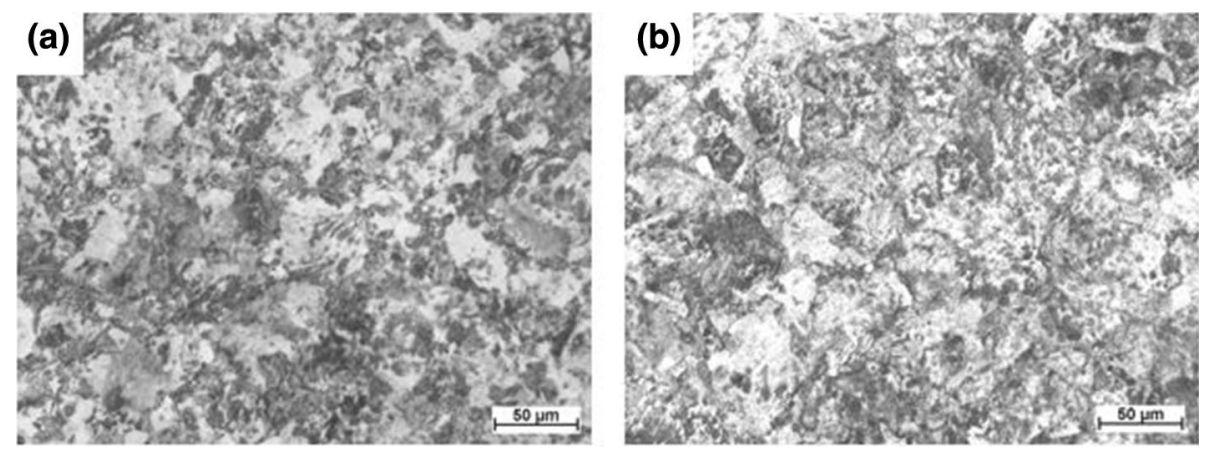

Fig. 6 Optical micrographs displaying the microstructure after etching for 44MnSiVS6 in its deep rolled condition (500-times magnification): (a) edge layer, (b) core

average integral width of the deep rolled condition increased to $2.17^{\circ}$.

In Table 3, the main results of the hardness and the x-ray diffraction measurements are shown. Independent from the angle considered, evolution of residual stress in-depth is similar. Highest residual stresses are found well below the surface $(0.5$ to $0.75 \mathrm{~mm})$.
The microstructure of a deep rolled 44MnSiVS6 crankshaft section is displayed in Fig. 6. The micrographs represent the edge layer (a) and the core area (b) of the fillet region. In comparison with the initial state, no significant difference in microstructure is obvious. In both cases, the figures show a coarse-grained microstructure composed of ferritic-perlitic grains. 


\subsection{Hardness, X-ray Diffraction and Microstructure Analysis (Induction Hardened Condition of 44MnSiVS6)}

The full-field hardness distribution for a 44MnSiVS6 crankshaft section in the fillet region and the related scale bar are displayed in Fig. 7. A total of 660 measuring points were recorded. Induced by induction hardening, a maximum hardness of $663 \mathrm{HV} 0.5$ and a minimum hardness of $290 \mathrm{HV} 0.5$ are established in the fillet region. With respect to all recorded measuring points, this corresponds to a total difference of $373 \mathrm{HV} 0.5$ and an average hardness of $429 \mathrm{HV} 0.5$. Figure 7 clearly points out that the induction hardening process does not lead to a uniform hardness distribution over the whole fillet region. Highest hardness values are seen near the surface and predominantly in the upper part of the fillet region, as can be deduced from the hardness map shown. Another important aspect to be considered is the steep decrease in the hardness value of about $100 \mathrm{HV} 0.5$ within the area labeled (c) (Fig. 7). In front of this drop, the hardness only decreases slightly. In the
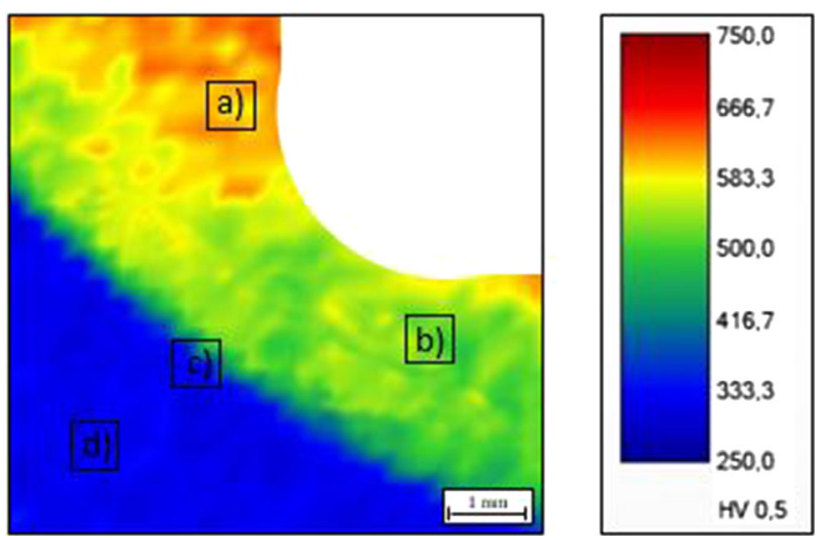

Fig. 7 Hardness distribution of the 44MnSiVS6 highlighting the steep gradient in the induction hardened area (Color figure online) area labeled (d), the hardness values approach the average hardness of the initial condition. These findings are further supplemented by hardness measurements and the X-ray diffraction measurements along the five defined angles plotted in the format already used in the previous sections.

In Fig. 8(a), the non-uniform hardness distribution can be comprehended by evaluating the hardness distribution along the five different angles. In Fig. 8(b) and (c), the results for residual stress and integral width are shown. The maximum residual stress values as well as the maximum values of the integral width are found at a depth of $0.25 \mathrm{~mm}$. The slope of the residual stress values thereafter is approximately linear until zero crossing occurs. Remarkably, the courses at $15^{\circ}$ and $30^{\circ}$ differ from the other 3 angles and exhibit higher compressive residual stresses. The zero crossing for all angles ranges from 1.85 to $3.4 \mathrm{~mm}$. In each direction, the values of the integral width shown in Fig. 8(c) slowly increase up to $0.25 \mathrm{~mm}$ and then decrease, so that the maximum values are present at $0.25 \mathrm{~mm}$. The entire depth profile contains two separate kinks. The first drop of the integral width is seen at a depth of $0.25 \mathrm{~mm}$ and applies to all angles. Depending on the direction characterized, the second drop is found in depths ranging from 1.5 to $2.5 \mathrm{~mm}$. Obviously, this second drop is much more pronounced than the first one.

The main results of the $\mathrm{x}$-ray diffraction and hardness investigations are listed in Table 4 . It can be seen that highest compressive residual stresses are present for the directions of $15^{\circ}$ and $30^{\circ}$, respectively, while alongside these angles compressive residual stresses prevail in greater depth. These two angles correspond to the upper part of the fillet region, where a higher hardness is seen (Fig. 8a). On the contrary, the induction hardening has significantly less influence alongside the direction $-15^{\circ}$.

Micrographs Fig. 9(a) and (b) reveal characteristics of the edge layer of the fillet region. The differences in microstructure provide an explanation for the variations found for the hardness values determined in these areas. In the near-surface region, a
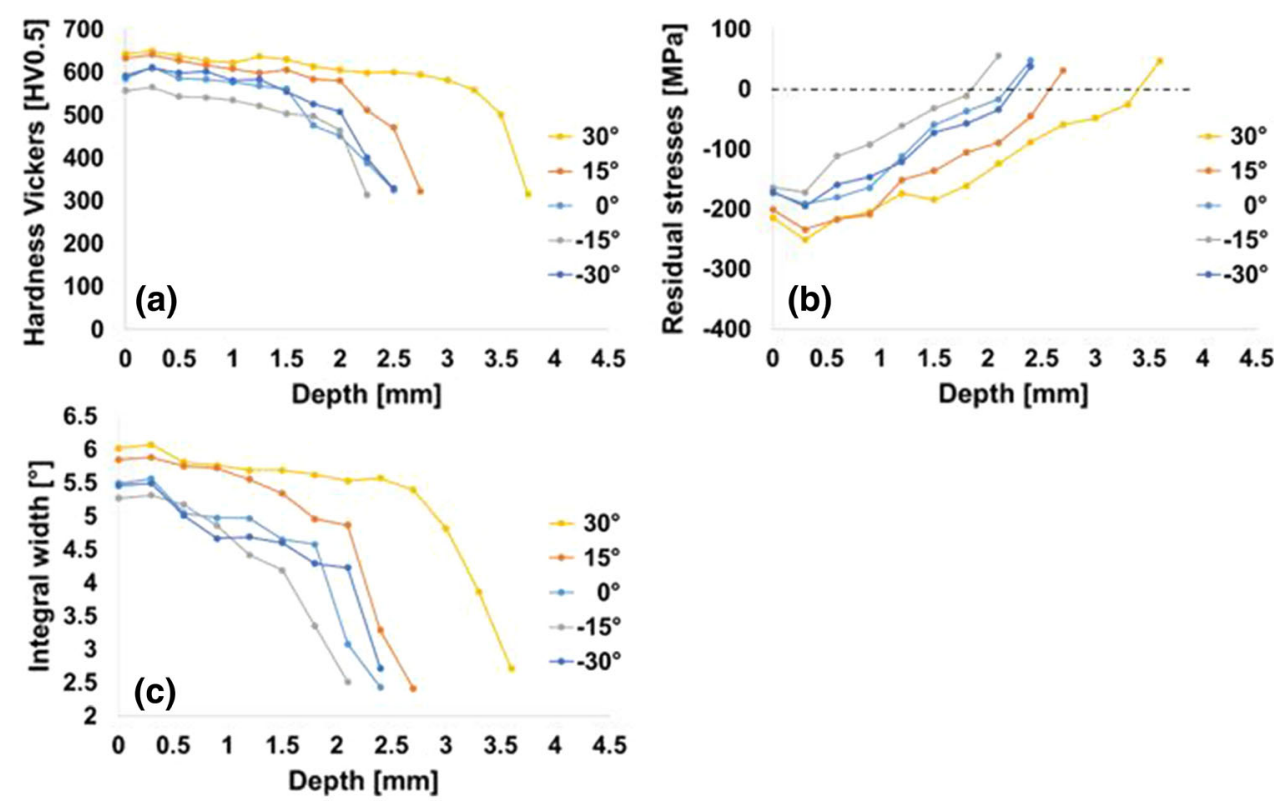

Fig. 8 44MnSiVS6 in its induction hardened condition: (a) hardness distribution, (b) residual stress distribution, (c) integral width distribution (Color figure online) 
Table 4 Quantitative results obtained from the hardness and the x-ray diffraction measurements (induction hardened condition of 44MnSiVS6)

\begin{tabular}{|c|c|c|c|c|c|}
\hline Angle, & $\begin{array}{c}\text { Residual stress near the } \\
\text { surface, MPa }\end{array}$ & $\begin{array}{c}\text { Max. compr. residual } \\
\text { stress, } \mathrm{MPa}\end{array}$ & $\begin{array}{c}\text { Zero crossing of residual } \\
\text { stress, } \mathrm{mm}\end{array}$ & $\begin{array}{l}\text { Max. integral } \\
\text { width, }{ }^{\circ}\end{array}$ & $\begin{array}{l}\text { Max. hardness, } \\
\text { HV }\end{array}$ \\
\hline 30 & -214 & -251 & 3.4 & 6.06 & 649 \\
\hline 15 & -201 & -234 & 2.55 & 5.88 & 626 \\
\hline 0 & -173 & -191 & 2.2 & 5.56 & 612 \\
\hline-15 & -164 & -172 & 1.85 & 5.31 & 565 \\
\hline-30 & -171 & -195 & 2.2 & 5.49 & 610 \\
\hline
\end{tabular}
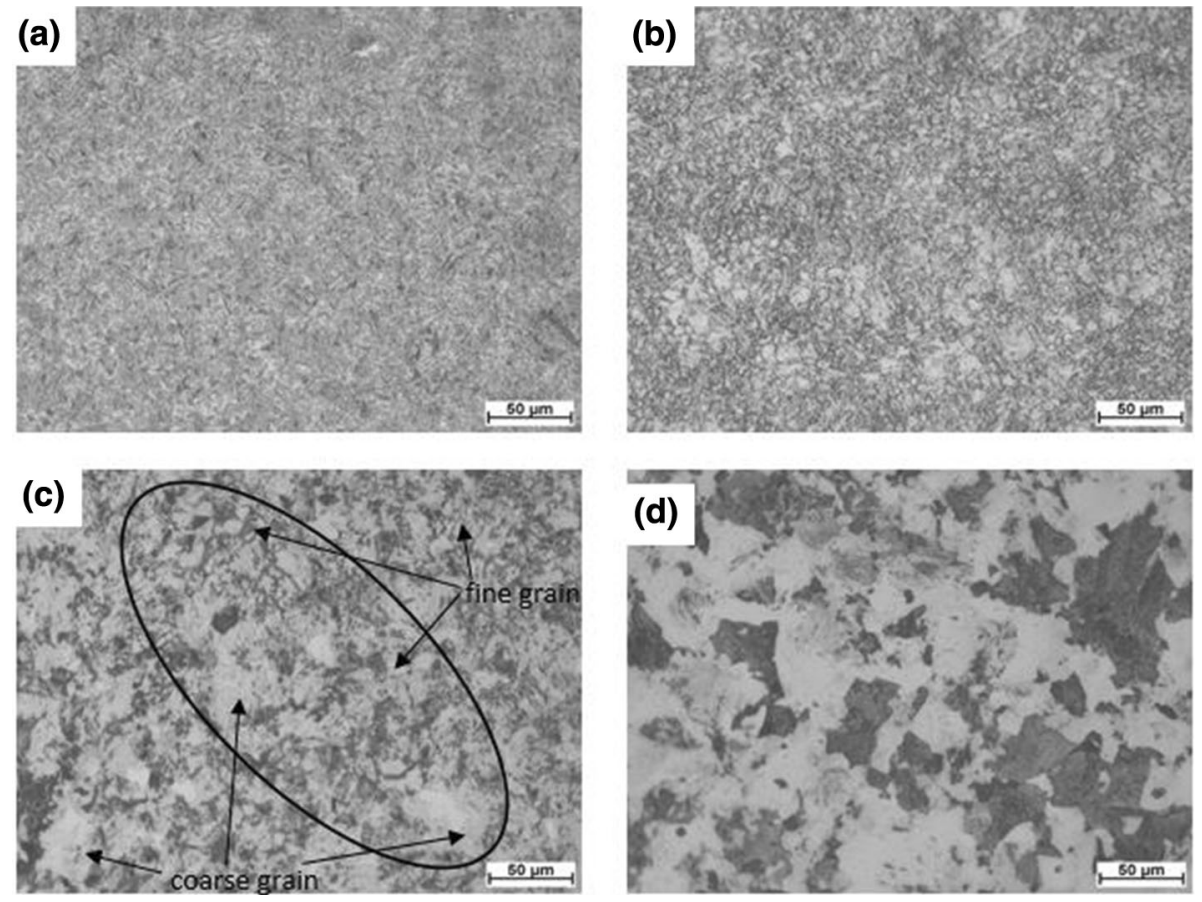

Fig. 9 Optical micrographs displaying the microstructure after etching for 44MnSiVS6 in its induction hardened condition (500-times magnification): (a) upper part, (b) near the running surface, (c) transition zone, (d) below the transition zone

fine-grained structure composed of bainite and martensite can be seen in Fig. 9(a). Phase analysis is supported by the hardness values found and high quenching rates prevailing in these regions. Direct evidence would, however, require further high-resolution microstructure analysis, clearly being beyond the scope of the present work. Figure 9(b) shows the microstructure near the running surface, which is dominated by relatively fine ferritic-perlitic grains. Due to partially incomplete austenitization and/or lower quenching rates, a predominantly martensitic/bainitic microstructure seems not to be achievable in line with the 44MnSiVSi6 time-temperaturetransformation (TTT) diagram. Differences in local heating and quenching rates can be traced back to the geometry described above. The hardness transition zone is depicted in Fig. 9(c) showing a pronounced change in grain size. In Fig. 9(d), a coarse-grained ferritic-perlitic microstructure is displayed being similar to the initial condition.

\subsection{EBSD Analysis}

In the following, the results obtained by the EBSD measurements for the differently treated crankshaft sections are displayed based on IPF and KAM maps as detailed in Sect.
2.3. Due to preparation-related rounding of the edges of the crankshaft fillet, EBSD measurements in direct vicinity of the surface could not be carried out. For this reason, the following EBSD results refer to areas at a distance of approx. $0.5 \mathrm{~mm}$ from the edge surface as is highlighted in the schematic displayed in the upper right of Fig. 10. As can be deduced from Fig. 7, detailing the hardness gradient within the induction hardened crankshaft fillet region by a hardness distribution map, the area probed by EBSD corresponds to an area of medium hardness and, thus, is hardly martensitically transformed.

Figure 10 displays the IPF maps for the 44MnSiVS6 in the initial condition (a), the deep rolled condition (b) and the induction hardened condition (c). In the initial condition, an average grain size of $4.1 \mu \mathrm{m}$ is determined. The average grain size for the deep rolled condition of $4.0 \mu \mathrm{m}$ is almost equal. Compared to these two conditions, a significant decrease in the average grain size of the induction hardened condition can be observed. Due to pronounced differences in microstructure along the fillet region (see Fig. 9a and b), a grain size determination was not carried out for the induction hardened condition. Figure 10(a) and (b) indicate no preferred grain orientation, whereas Fig. 10(c) indicates a preferred $\langle 111\rangle$ 

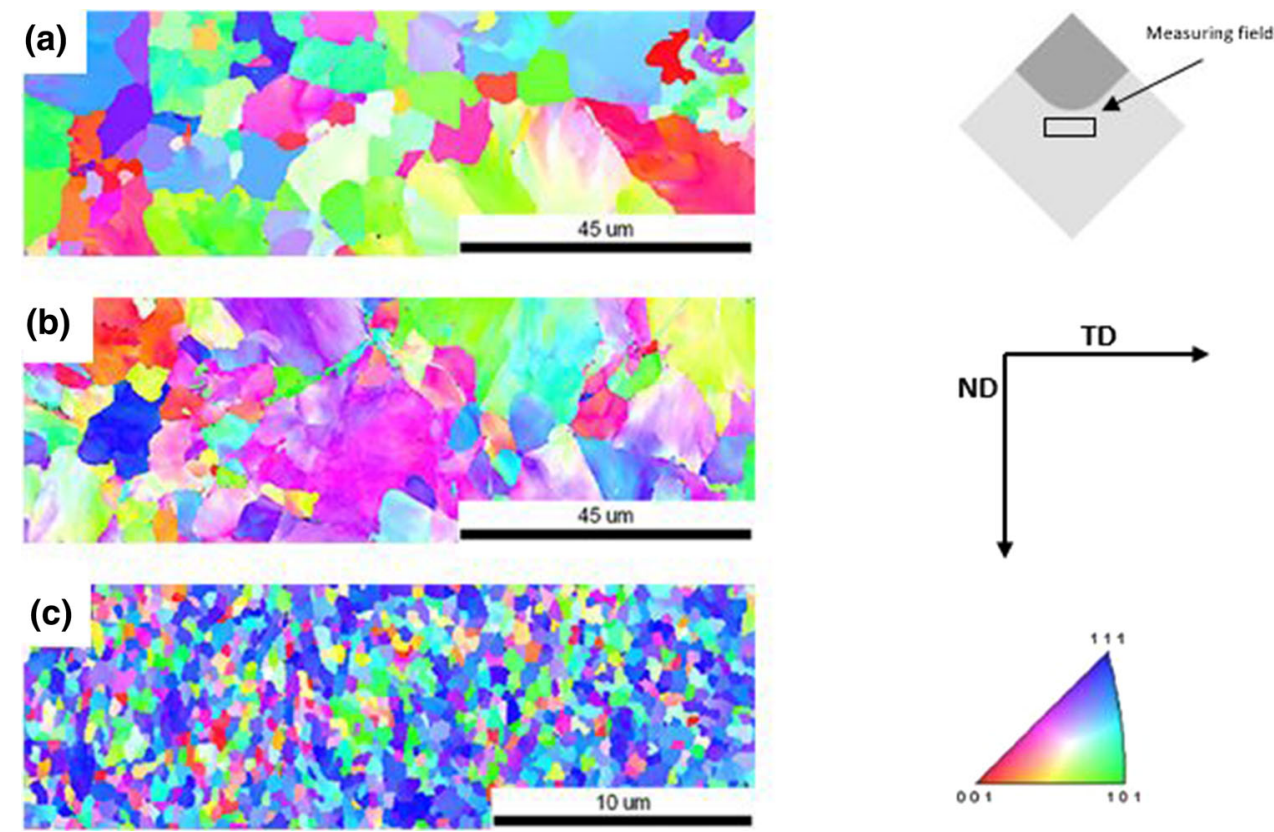

Fig. 10 IPF maps for the (a) initial condition, (b) deep rolled condition, (c) induction hardened condition. Grain orientations are plotted. Color coding of grains is in accordance to the standard triangle shown on the right. Please note the different scale bar for the induction hardened condition (Color figure online)
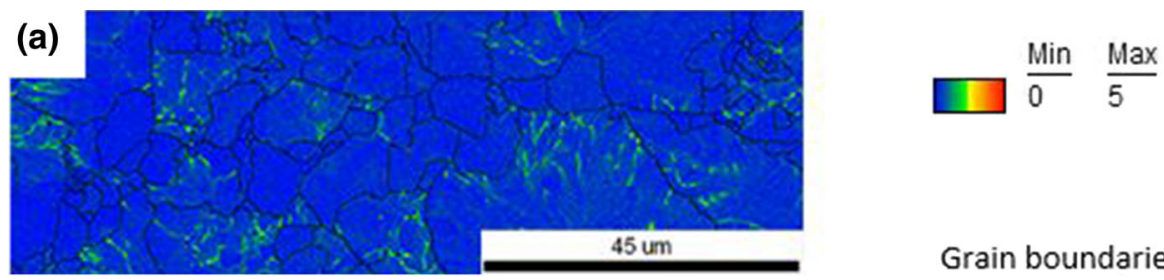

\section{Grain boundaries:}
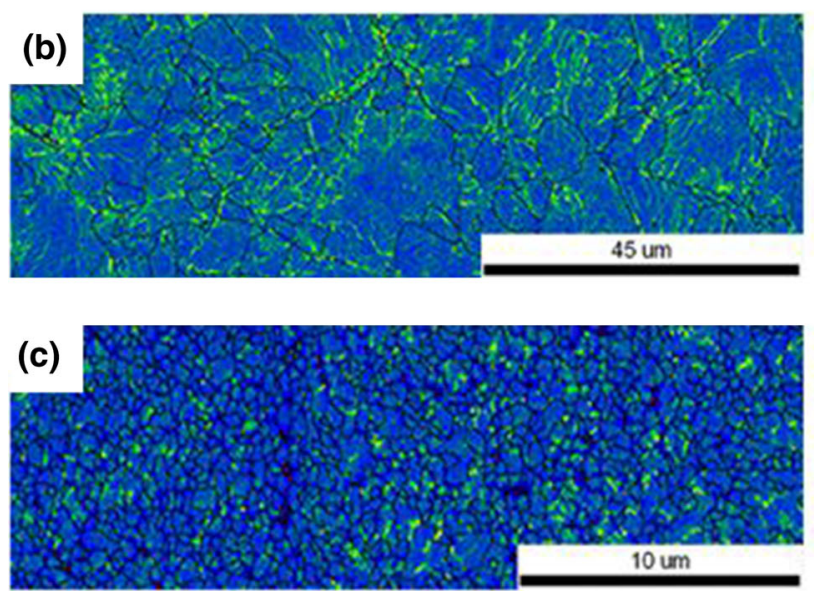

Fig. 11 KAM maps for the (a) initial condition, (b) deep rolled condition, (c) induction hardened condition. Local misorientation is coded by the color in accordance to the scale shown to the upper right. High-angle boundaries $\left(>15^{\circ}\right)$ are superimposed by black lines. Please note the different scale bar for the induction hardened condition (Color figure online)

orientation. Moreover, in the deep rolled condition color gradients primarily at grain boundaries can be seen. Such kind of feature is not seen in the initial and induction hardened states. To further examine the role of the surface treatments on the evolution of local misorientations within the grains, KAM maps of the initial condition, the deep rolled condition and the induction hardened condition are shown in Fig. 11(a), (b) and (c). Local misorientation thereby is coded by the color in accordance to the scale shown to the upper right of Fig. 11.

The AoI of the initial condition shows almost homogeneous misorientation values across the full scanning field. Only a few heterogeneities (marked green and yellow) are present within some grains. As deduced from Fig. 11(a), low misorientation with an average KAM value of $0.52^{\circ}$ prevails. Figure 11(b) 
depicts the deep rolled condition. In this condition, the average KAM value increased to $0.91^{\circ}$. Figure 11(c) shows the AoI within the gradient region of the induction hardened area. In this case, the average KAM value only slightly increased to $0.65^{\circ}$ and, thus, is quite similar to the initial condition.

\subsection{ECCI Analysis}

Figure 12 depicts the results obtained by ECCI analysis for the initial condition, the deep rolled condition and the induction hardened condition. Analysis was conducted for all conditions in the same areas as in case of EBSD. All three material conditions were recorded at different magnifications due to differences in size of microstructural features prevailing. Figure 12(a) and (b) show microstructural details being representative for the initial state. As marked in Fig. 12(b) (white circles), occasional crystal defects mainly accumulate in direct vicinity of grain boundaries and triple points. Microstructural changes induced by deep rolling are depicted and highlighted in Fig. 12(c) and (d). Basically, a strong accumulation and superposition of different crystal defects near grain boundaries is revealed. Moreover, a vein structure is seen in between the lamellar features (white arrow). In Fig. 12(e) and (f), the microstructural impact of the induction hardening procedure is illustrated. Figure 12(f) also reveals a pronounced concentration and superposition of crystal defects.
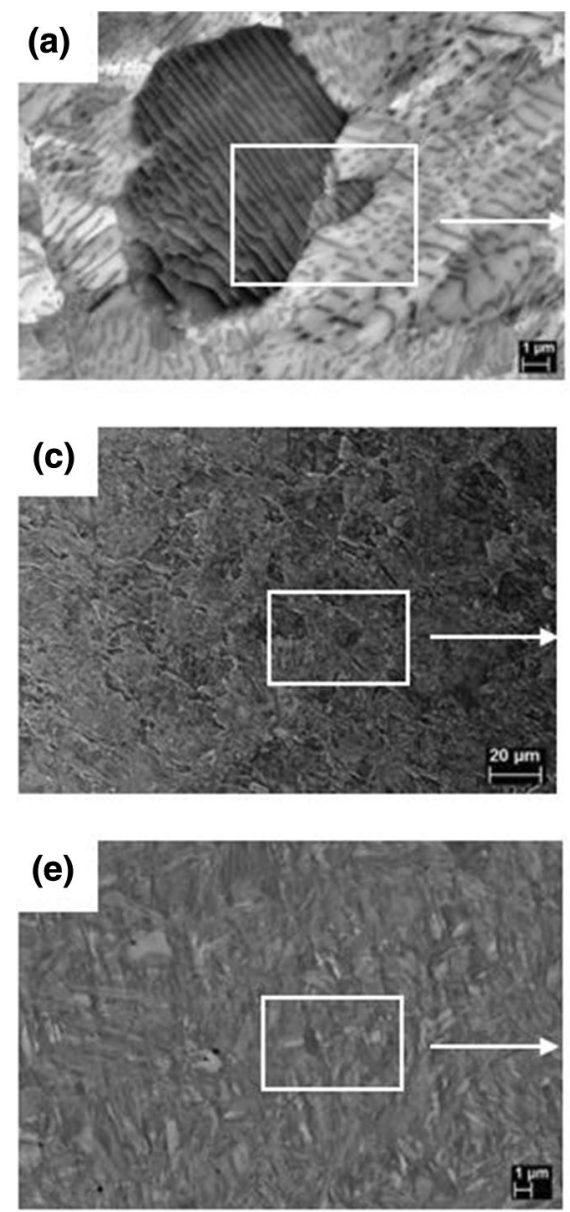

\section{Discussion}

In the present work, crankshaft sections in three different material states were investigated, (see Fig. 13). In the initial state, the crankshafts were hot forged. Thus, deformation took place above recrystallization temperature. Afterward, the crankshafts were air-cooled in a controlled fashion down to room temperature in order to avoid high thermal gradients and distortion of the component, respectively. Subsequently, the bearing journals and the fillets were conventionally machined. As detailed before, this condition is provided for reference in the present work.

In its initial state, the 44MnSiVS6 microalloyed steel is characterized by a homogeneous hardness distribution as shown in Fig. 3(a). Deviating residual stress values determined by XRD ( $\sin ^{2} \psi$-method) can be seen in Fig. 3(b); however, absolute values remain on a very low level. On the contrary, integral width results as displayed in Fig. 3(c) (also obtained by the XRD measurements) remain absolutely constant. Thus, hardness and integral width values indicate uniform local properties and material conditions, which is also in line with the homogeneous formation of a ferritic-perlitic microstructure in the edge and core areas of the fillet as depicted in Fig. 4. These homogeneous microstructures can be explained by the recrystallization process induced by forging and controlled aircooling, forming a new, almost stress-free and relatively soft
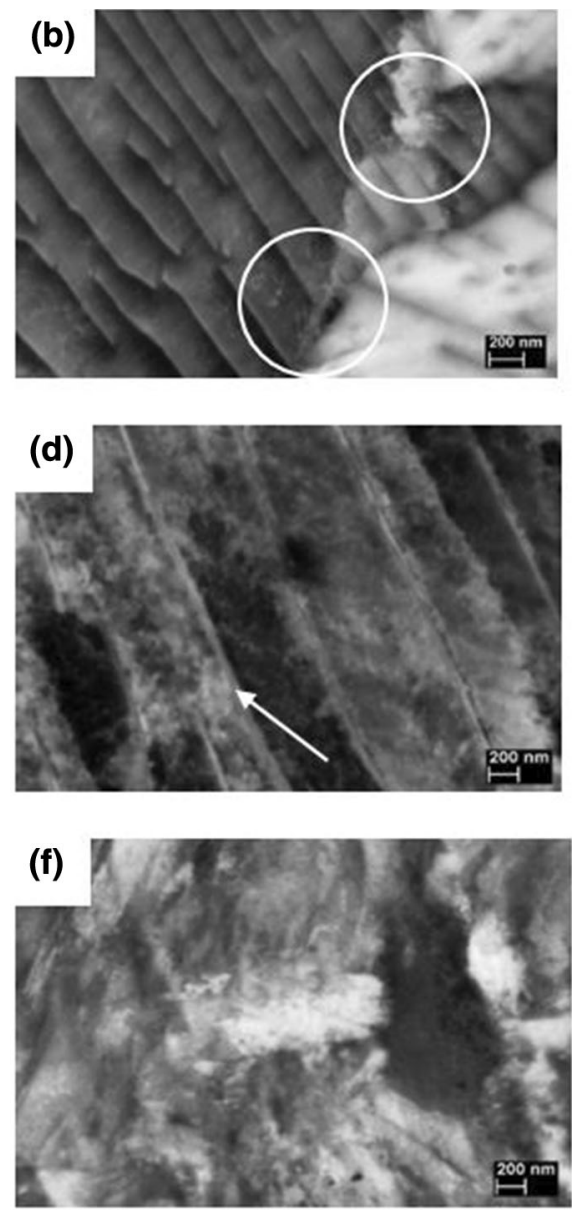

Fig. 12 ECCI micrographs revealing representative microstructural features for (a), (b) the initial condition; (c), (d) the deep rolled condition; (e), (f) the induction hardened condition. See text for details 


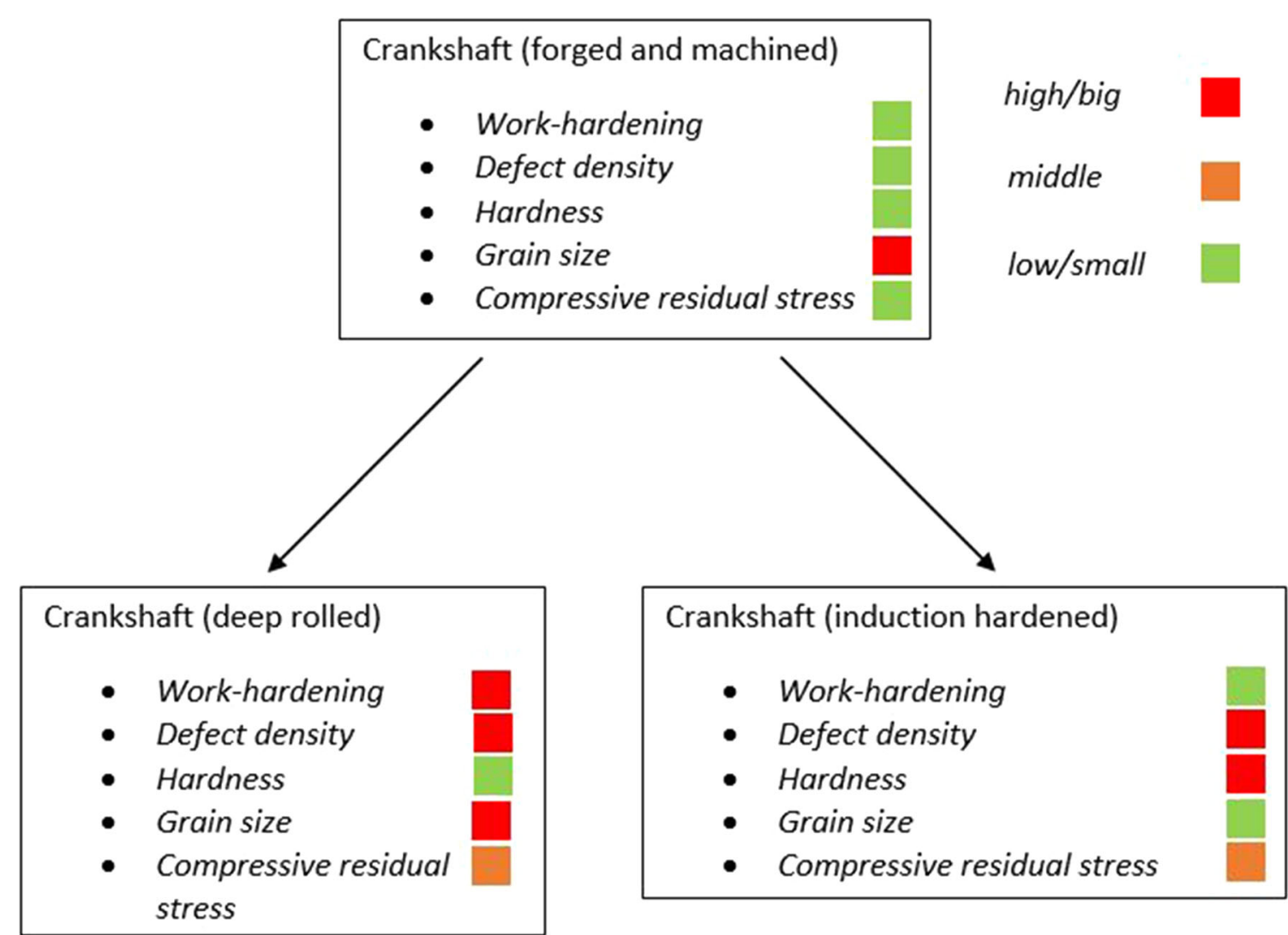

Fig. 13 Schematic illustration highlighting general characteristics of the analyzed material conditions (Color figure online)

microstructure (Ref 27). In order to provide for profound information concerning microstructural changes (beyond conventional metallographic investigations employing optical microscopy), EBSD and ECCI measurements were carried out. In contrast to conventional optical microscopy, EBSD is able to reveal additional information such as phase fractions, grain orientation (deviation) and grain size. In this context, randomly oriented grains can be observed in the IPF map (Fig. 10a), indicating that the machining process did hardly influence the grain orientation in the near-surface areas. Furthermore, the initial material condition is characterized by a low KAM value of $0.52^{\circ}$ (calculated from Fig. 11a), which is also supported by ECCI results disclosing only few occasional defects predominantly at grain boundaries and triple points as detailed in Fig. 12(a) and (b). In fact, low misorientation and defect density are in good agreement with the homogeneous and low integral width distribution in the fillet region. Scatter seen in case of residual stress values is expected to stem from a superposition of air-cooling and machining induced effects (as detailed above it has to be considered that absolute values are on a very low level in this condition). Independent of the scatter seen in Fig. 3(b), tendencies observed can be explained based on the edge-core model for the cooling process (Ref 28). In fact, such residual stress distributions on a fairly low level are in line with the controlled air-cooling procedure performed. With regard to machining operations conducted upon heat treatment, the residual stress state results from a superposition of process-related mechanical and thermal effects, such that tensile and compressive residual stresses are superimposed (Ref 14). Based on data available in the literature, significant residual stresses can be expected after machining down to a depth of approx. $200 \mu \mathrm{m}$ (Ref 14). However, based on sample preparation procedures applied, measurements could not be carried out in this area in the present work. Thus, effects of aircooling dominate the stress state resolved by XRD. It is well known that far-reaching residual stresses of the first type can evolve induced by temperature differences during cooling, even upon slow cooling, among other microstructural processes (Ref 29). In principle, the reason for the discrepancy between the courses of the trendlines for integral width and residual stress is seen in the elementary microstructural factors being exploited for determination of those two values. As already detailed in the introduction section, the integral width reflects strain hardening (or the somehow chaotic arrangement of microscopic residual stresses) of the material. As these chaotic microscopic stress fields strongly affect hardness being determined by indentation as well, the well-defined correlation between the hardness measurements and the integral width results is in good agreement as detailed in Sect. 3.1. Residual stresses, however, have to be distinguished and evaluated differently. For this reason, residual stresses of I. kind, II. kind and III. kind have to be considered as it is known since decades (Ref 30, 31). In case of the far-reaching residual stresses, being of utmost importance for final properties of the treated component, residual stresses of I. kind have to be separated from stresses of II. kind and III. kind. Analysis of residual stresses by means of XRD, however, is sensitive to residual stresses of I. kind and II. kind, such that locally different phase fractions may contribute to the final absolute values determined in a single phase. All results presented in the present work were obtained on the basis of the (211) plane of the ferrite. Phase analysis is provided for all conditions highlighting the dominance of ferritic phase frac- 
tions in all conditions. Thus, any corrections with respect to different prevailing phases and additional measurements by techniques only sensitive to residual stresses of I. kind were not conducted.

Deep rolling was carried out starting from the initial condition of the crankshafts as detailed in Fig. 13. The corresponding process parameters can be found in Sect. 2. In light of hardness data shown in Fig. 5(a), uniform distributions across the fillet region can be seen. Due to the localized plastic deformation in the surface and subsurface areas induced by the deep rolling process, a characteristic course of compressive residual stresses evolves (Fig. 5b). In contrast to the initial condition, scatter in local properties is significantly reduced. The distribution of the integral width is displayed in Fig. 5(c). In contrast to the initial state, the average integral width increased to $2 \cdot 17^{\circ}$. Hardness and integral width data point out a homogeneous material state, which can also be confirmed by the optical micrographs (Fig. 6). Thus, the slight increase in hardness and integral width in the near-surface region can be interpreted as a clear indicator for local plastic deformation and strain hardening (Ref 32). According to Macherauch, an increase in integral width goes along with increase in microtensions (residual stresses of the III. kind) (Ref 31). Generally, all kinds of lattice defects such as dislocations, interfaces, and coherent and partially coherent precipitates, can induce a broadening effect of the interference line profile (Ref 32, 33). For this reason, EBSD and ECCI can be employed in addition to XRD for fast qualitative evaluation of elementary sources of plastic deformation and their distribution by analyzing color gradients (IPF and KAM) as well as the defect density on the basis of local brightness differences (ECCI) in the respective maps. In order to account for this kind of analysis, measurements were carried out in the areas close to the edges. With regard to the IPF maps depicted in Fig. 10, the average grain size upon deep rolling is almost equal as compared to the initial condition, which is in line with the micrographs detailed in Sects. 3.1 and 3.2. In contrast to the initial condition, an increase in presence of color gradients, primarily being seen at grain boundaries, can be observed in the IPF map. From a qualitative point of view, this already implies increased local misorientation and localized plastic deformation in given areas imposed by mechanical surface treatment and aligns with increased integral width values as detailed in Fig. 5(c). Similar results highlighting local plastic deformation with regard to the analysis of IPF data were shown by Hsiao et al. (Ref 34, 35) and Schayes et al. (Ref 23). Furthermore, the average KAM value for the deep rolled condition increased to $0.91^{\circ}$ as detailed in Fig. 11(b). Highest KAM values at grain boundaries and triple points are in agreement with the qualitative assessment based on the IPF maps. Changes in misorientation revealed can be rationalized based on geometrically necessary dislocations (GND) in accordance to literature (Ref 22, 23). Basically, two different kinds of elementary mechanisms have to be considered for analysis of plastic deformation of polycrystalline materials. Firstly, geometrically necessary dislocations (GNDs) are needed, allowing grains to develop locally due to locally differing deformation in a polycrystalline material. In fact, GNDs prevent the polycrystalline material from immediate failure. GNDs are mainly located near grain boundaries, where incompatibility stresses are highly effective. Secondly, statistically stored dislocations (SSD) have to be considered. SSDs, distributed homogeneously within the microstructure lead to general hardening of the crystal (Ref
36), however, are affected by individual grain orientations. Experimental data indicate an increase in GND density in the vicinity of grain boundaries and triple points in present work. From the orientation distribution highlighted in the IPF map, strain incompatibilities in the respective areas can be deduced (Ref 23, 37). Since micro-tensions stemming from dislocations affect the experimentally determined integral width values, KAM analysis is in excellent agreement with higher integral width values found (cf. Fig. 5c), i.e., both techniques imply a higher density of lattice defects. However, inadequate sample preparation can influence these values significantly (Ref 21). In order to exclude misleading interpretation of data due to residue from sample preparation, ECCI was carried out to provide for additional in-depth information on the overall microstructure appearance of the different material conditions. For this purpose, grain boundaries and triple points were investigated in order to establish relations to the KAM maps obtained in these areas. As will be discussed in the following, ECCI results confirm EBSD findings. As a result, an inadequate sample preparation can be excluded.

Due to large plastic strain imposed in the fillet region by the deep rolling process, individual crystal defects, such as single dislocations, could not be resolved anymore by ECCI. A very high dislocation density prevails, while the microstructural features seen, i.e., lamellar arrangements containing vein structures (Fig. 12d), imply directionality of stress fields resulting thereof. Results are in good agreement with findings based on KAM detailed in Fig. 11. In principle, deep rolling is a non-cutting process allowing to reduce the surface roughness and, in addition, to impose an increase in defect density and hardening as well as to promote compressive residual stresses in the surface layer (Ref 38). Compressive residual stresses are the key to reduce notch effects and extend fatigue lives by preventing initiation and the growth of local defects (Ref 16). In general, a distinction can be made between two elementary processes during deep rolling, whereby two different deformation processes have to be considered accordingly. On the one hand, the surface pressure caused in the contact zone between the workpiece and the tool (Hertzian contact stresses) leads to a triaxial stress state that varies with surface distance. Actual values depend on the contact geometry. These lead to smoothing as well as friction effects in direct vicinity of the surface. As soon as the yield strength of the material is exceeded at a certain surface distance, plastic deformations occur in these regions. On the other hand, material areas in the contact zone are plastically stretched directly at the surface. In both cases, the resulting residual stress state is associated with defect induced hardening and softening effects (Ref 38). The process-related decrease in the plastic deformation from the top surface to the base metal well correlates with the hardness and integral width distributions shown. Although a characteristic residual stress condition is established after deep rolling, the courses of the residual stress profiles differ considerably from the trends revealed by hardness and integral width. As detailed and discussed above, the microscopic contributions of defects introduced, i.e., residual stresses of III. kind, are not effective in increasing residual stress, however, significantly contribute to strain hardening. Thus, not all defects introduced by deep rolling contribute to residual stresses established. As induced by the Hertzian contact stresses, the maximum values of residual stress occur in subsurface regions. Thus, due the stress state imposed by deep rolling, only in these subsurface layers directionality of stress fields is most pronounced. Relevant 
microstructural features have been revealed by ECCI in the present work. In consequence, microstructure evolution upon deep rolling represented by changes in the integral width is well reflected by the courses of the hardness distribution, while only weakly defined interrelations between the hardness distribution and residual stress states can be seen in the hardened layers. A schematic illustration highlighting the deep rolled material properties in comparison with the initial state can be seen in Fig. 13.

In contrast to the deep rolled condition, the induction hardened region (Fig. 7) reveals a non-uniform microstructure, i.e., a relatively steep gradient, within the treated fillet region. After induction hardening, the hardness level of the crankshaft section increases substantially. Highest hardness values are seen near the surface and predominantly in the upper part of the fillet region. A reason for this is thought to be rooted in the geometry of the sample (Fig. 2a). A smaller component volume in the upper part of the fillet results in faster heating as well as changes of the subsequent cooling rate as compared to heating and cooling of the component volume near the running surface. Thus, hardness values near the running surface (Fig. 7b) are lower in comparison with the upper part (Fig. 7a) of the fillet region. The influence of the thermal treatment is characterized by a higher penetration depth as compared to deep rolling; however, hardness declines abrupt when initial microstructural features prevail. The non-uniform hardness distribution can also be comprehended by the hardness values along the five defined angles (Fig. 8a). Comparing the hardness mapping displayed in Fig. 7 and trends deduced from Fig. 8(a), results are in good agreement. Even if the distribution of hardness is significantly different, the residual stress distribution is almost equal upon deep rolling (mechanical treatment) and induction hardening (thermal treatment) (as shown in Fig. 5b and 8b). These findings for the different material conditions are illustrated schematically in Fig. 13.

Also upon induction hardening, hardness distribution and courses of integral width show a good fit. Upon induction hardening, hardness and integral width values (shown in Fig. 8a and c) strongly increased compared to the initial state (see Fig. 13). In fact, the integral width depth profile in Fig. 8(c) is well reflected by the hardness distribution. Figure 9 highlights the heterogeneous microstructure within the gradient region of the induction hardened area. In particular, the local drop of hardness of approximately $100 \mathrm{HV} 0.5$ in the transition zone can be rationalized based on Fig. 9(c) showing a significant change in grain size and morphology in this area. Figure 9 clearly reveals distinct differences in microstructure evolution from the edge layer down to a depth of about $4 \mathrm{~mm}$. These differences in local hardness can be rationalized based on differences in local thermal history with regard to the TTT diagram of 44MnSiVS6, i.e., geometry-related differences in absolute temperatures upon heating and most importantly pronounced differences in quenching rates. For further analysis, SEM-based methods, i.e., EBSD and ECCI, were applied due to their high lateral resolution. As revealed by the IPF map in Fig. 10(c), the apparent grain size in the gradient region is significantly reduced after induction hardening, i.e., at least in the area probed; however, grain size in this condition is generally subjected to pronounced local deviation. In Fig. 11(c), the KAM map for the induction hardened fillet area is shown. In this case, only a slight increase in the average $\mathrm{KAM}$ to $0.65^{\circ}$, as compared to the initial condition, is resolved. Obviously, highest values found for the integral width in this condition are not adequately represented by the KAM values. The mean KAM values determined for the deep rolled condition are significantly higher. Depending on the parameters employed for EBSD analysis (including step size and threshold value, cf. Sect. 2.3.4), the KAM map is not able to fully reveal all important features within the induction hardened fillet area, as this condition is characterized by diverse features on different length scales down to the submicron regime in the gradient region. Most importantly, the point-to-point analysis conducted in the present work for calculation of KAM values is only sensitive to relatively smooth gradual changes on the micron scale, but not to abrupt changes on the submicron scale. In consequence, the SEM-based EBSD technique is only capable of identifying areas of concentrated strain or local misorientation within a microstructure on the micron scale, however, not well suited for identifying the actual magnitude of strain in those areas, as has been discussed in literature (Ref 39), and changes on the submicron level. Contributions of different microstructural defects on integral width have to be considered at this point. On the one hand, the significant increase in integral width after induction hardening can be attributed to a high density of inhomogeneous micro-tensions imposed by quenching. On the other hand, the interference line broadening effect is also strongly affected by grain and crystallite size, respectively (Ref 32). In this context, ECCI reveals fundamentally different microstructural features in the induction hardened surface region (Fig. 12e and $\mathrm{f}$ ) as compared to the deep rolled condition. Figure 12(f) depicts a strong accumulation and superposition of crystal defects; however, a directionality of defects can hardly be seen. Basically, the induction hardening process can be subdivided into three main stages - starting with the heating and the holding period up to the quenching process. By heating to the austenitizing temperature, residual stresses present in the workpiece stemming from previous machining operations are relieved. However, new residual stresses are created during cooling/ quenching. Firstly, these are the result of the localized dilatations leading to local plastic deformation during the quenching process according to the edge-core model. Secondly, a superposition with stresses resulting from the volume increase imposed by the martensitic phase transformation is effective (Ref 28, 40). Due to the high lattice distortion during martensite formation, which is basically predetermined by the content of dissolved carbon, an increase in dislocation density is induced (Ref 41). As another factor, for the phase transformation the number of nuclei as well as the cooling rate is of utmost importance with respect to the evolving grain size (Ref 42). In this regard, the decreasing cooling rate from the surface to the core of the crankshaft seems to be a determining factor for the steady increase in local grain size.

The microstructural development caused by induction hardening can be revealed experimentally by the hardness, residual stress and integral width distributions. In addition, SEM-based methods can help to achieve an in-depth microstructural interpretation. Although the mean integral width for the induction hardened condition is much higher than for the deep rolled condition, residual stresses found are on the same level (see Fig. 13). This clearly indicates that the stress fields of defects resulting from induction hardening are somehow less directional. 


\section{Summary}

The present work examined the evolution of hardness and residual stresses for a medium carbon 44MnSiVS6 microalloyed steel being widely used for highly loaded components in the automotive sector. On the basis of the results shown for the initial state of the steel as well as for the deep rolled and the induction hardened crankshaft fillets only a partial, weak relation between hardness and residual stress states determined by x-ray diffraction measurements could be observed. As schematically displayed in Fig. 13, generalizations toward quantification could not be made on this basis. However, a good conformity between the hardness measurements and the integral width results could be established for the investigated material conditions. The microstructures of the conditions considered are fundamentally different in terms of contribution of individual defects and strengthening mechanisms, respectively. Especially the deep rolled condition is characterized by an arrangement of defects implying directionality of stress fields linked thereto. As microstructural features seen are expected to affect hardness and integral width in different ways, a quantitative correlation upon different surface treatments could not be made. Moreover, a direct and unique correlation between macroscopic residual stresses and hardness or integral width could not be deduced from the results detailed. Hardness and integral width distributions, however, allow for an assessment of the thickness of the affected surface layer and, hence, also of the layer thickness being affected by compressive residual stress. For an in-depth analysis with regard to microstructural changes and crystal defects, SEM-based techniques such as EBSD and ECCI have proven to be highly effective. Basically, residual stresses and integral widths reflect internal component stresses of different kinds and, thus, on different scales. Consequently, separate evaluation of hardness and residual stress profiles is indispensable for a comprehensive quality assessment.

\section{Acknowledgments}

The authors gratefully acknowledge funding from the EC Research Fund for Coal and Steel, RFCS, for the project Stiffcrank, No. 754155.

\section{Funding}

Open Access funding enabled and organized by Projekt DEAL.

\section{Open Access}

This article is licensed under a Creative Commons Attribution 4.0 International License, which permits use, sharing, adaptation, distribution and reproduction in any medium or format, as long as you give appropriate credit to the original author(s) and the source, provide a link to the Creative Commons licence, and indicate if changes were made. The images or other third party material in this article are included in the article's Creative Commons licence, unless indicated otherwise in a credit line to the material. If material is not included in the article's Creative Commons licence and your intended use is not permitted by statutory regulation or exceeds the permitted use, you will need to obtain permission directly from the copyright holder. To view a copy of this licence, visit http://creativecommons.org/licenses/by/4.0/.

\section{References}

1. Y.S. Ko, J.W. Park, H.O. Bhan, H. Park, and J.D. Lim, Fatigue Strength and Residual Stress Analysis of Deep Rolled Crankshafts, in Fatigue Strength and Residual Stress Analysis of Deep Rolled Crankshafts. SAE International400 Commonwealth Drive, Warrendale, PA, United States, 2005

2. D.K. Matlock, K.A. Alogab, M.D. Richards, and J.G. Speer, Surface Processing to Improve the Fatigue Resistance of Advanced Bar Steels for Automotive Applications, Mat. Res., 2005, 8(4), p 453-459. h ttps://doi.org/10.1590/s1516-14392005000400017

3. P. Citti, A. Giorgetti, and U. Millefanti, Current Challenges in MATERIAL choice for High-Performance Engine Crankshaft, Proc. Struct. Integ., 2018, 8, p 486-500. https://doi.org/10.1016/j.prostr.201 7.12.048

4. V. Savaria, H. Monajati, F. Bridier, and P. Bocher, Measurement and Correction of Residual Stress Gradients in Aeronautical Gears After Various Induction Surface Hardening Treatments, J. Mater. Process. Technol., 2015, 220, p 113-123. https://doi.org/10.1016/j.jmatprotec. 2014.12.009

5. F. Garcia, Crankshaft Fillet Hardening: Challenges and Prospects, Industrial Heating, 2014, 12, p 47-48

6. D. Coupard, T. Palin-luc, P. Bristiel, V. Ji, and C. Dumas, Residual Stresses in Surface Induction Hardening of Steels: Comparison Between Experiment and Simulation, Mater. Sci. Eng., A, 2008, 487(1-2), p 328-339. https://doi.org/10.1016/j.msea.2007.10.047

7. P. Delgado, I.I. Cuesta, J.M. Alegre, and A. Díaz, State of the art of Deep Rolling, Precis. Eng., 2016, 46, p 1-10. https://doi.org/10.1016/j. precisioneng.2016.05.001

8. J. Barglik and A. Smalcerz, 2.6 Surface Induction Hardening, in Comprehensive Materials Finishing, Elsevier 2017, p. 154-170

9. M. Leitner, R. Aigner, and D. Dobberke, Local Fatigue Strength Assessment of Induction Hardened Components Based on Numerical Manufacturing Process Simulation, Proc. Eng., 2018, 213, p 644-650. https://doi.org/10.1016/j.proeng.2018.02.060

10. A. Manouchehrifar and K. Alasvand, Finite Element Simulation of Deep Rolling and Evaluate the Influence of Parameters on Residual Stress. Recent Researches in Applied Mechanics. WSEAS Press, 2009, p. $121-127$

11. H. Kristoffersen and P. Vomacka, Influence of Process Parameters for Induction Hardening on Residual Stresses, Mater. Des., 2001, 22(8), p 637-644. https://doi.org/10.1016/s0261-3069(01)00033-4

12. A. Tjernberg, Fatigue Lives for Induction Hardened Shafts with Subsurface Crack Initiation, Eng. Fail. Anal., 2002, 9(1), p 45-61. h ttps://doi.org/10.1016/s1350-6307(00)00036-4

13. E. Hajyheydari, M. Liewald, and A. Felde. Technologische Eigenschaften von AFP-Stahl im Temperaturbereich zwischen Raumtemperatur und $500^{\circ}$ C. SchmiedeJOURNAL, 2012, p. 54-57

14. H.-D. Tietz, Grundlagen der Eigenspannungen: Entstehung in Metallen, Hochpolymeren u. silikatischen Werkstoffen, Messtechnik u. Bewertung. 1. Aufl. Deutscher Verlag für Grundstoffindustrie, Leipzig 1983

15. C. Achmus, J. Betzold, and H. Wohlfahrt, Messung von Festwalzeigenspannungsverteilungen an Bauteilen, Mat.-wiss. $u$. Werkstofftech., 1997, 28(4), p 153-157. https://doi.org/10.1002/mawe. 19970280405

16. J. Betzold, J. Pucelik, and S. Eisenberg, Eigenspannungen als Messgröße zur Qualitätssicherung, Mat.-wiss. u. Werkstofftech., 2007, 38(4), p 263-273. https://doi.org/10.1002/mawe.200700133

17. DIN EN ISO 6507. Metallische werkstoffe - Härteprüfung nach Vickers -Teil 1: Prüfverfahren, 2018, 2018

18. E. Macherauch and P. Müller, Das $\sin ^{2}-\Psi$ Verfahren der röntgenographischen Spannungsmessung, Zeitschrift für angewandte Physik, 1961, 13, p 305-316

19. V. Savaria, F. Bridier, and P. Bocher, Computational Quantification and Correction of the Errors Induced by Layer Removal for Subsurface Residual Stress Measurements, Int. J. Mech. Sci., 2012, 64(1), p 184195. https://doi.org/10.1016/j.ijmecsci.2012.07.003 
20. P.S. Prevéy, Ed., X-ray Diffraction Residual Stress Techniques. Metals Handbook 10, ASM International, Metals Park, 1986

21. A.J. Schwartz, M. Kumar, B.L. Adams, and D.P. Field, Electron Backscatter Diffraction in Materials Science, Springer, Boston, MA, 2009

22. P.J. Konijnenberg, S. Zaefferer, and D. Raabe, Assessment of Geometrically Necessary Dislocation Levels Derived by 3D EBSD, Acta Mater, 2015, 99, p 402-414. https://doi.org/10.1016/j.actamat. 2015.06.051

23. C. Schayes, J. Bouquerel, J.-B. Vogt, F. Palleschi, and S. Zaefferer, A Comparison of EBSD Based Strain Indicators for the Study of Fe-3Si Steel Subjected to Cyclic Loading, Mater. Charact., 2016, 115, p 6170. https://doi.org/10.1016/j.matchar.2016.03.020

24. S. Zaefferer and N.-N. Elhami, Theory and Application of Electron Channelling Contrast Imaging Under Controlled Diffraction Conditions, Acta Mater., 2014, 75, p 20-50. https://doi.org/10.1016/j.actama t.2014.04.018

25. A. Weidner, A. Glage, L. Sperling, and H. Biermann, Observation of Stacking Faults in a Scanning Electron Microscope by Electron Channelling Contrast Imaging, IJMR, 2011, 102(1), p 3-5. https://doi. org/10.3139/146.110448

26. T. Taniguchi, Y. Kaneko, and S. Hashimoto, ECCI, Observations of Dislocation Structures Around Fatigue Cracks in Ferritic Stainless Steel Single Crystals, IOP Conf. Ser. Mater. Sci. Eng, 2009, 3, p 12020. h ttps://doi.org/10.1088/1757-899x/3/1/012020

27. V. Läpple, Wärmebehandlung des Stahls: Grundlagen, Verfahren und Werkstoffe 9., aktualisierte Aufl, Verl. Europa-Lehrmittel, HaanGruiten, 2006

28. A. Grüning, Thermo-mechanisch gekoppelte Experimente zur Beurteilung der Schädigungsentwicklung an Werkzeugen zur Warmumformung, Kassel Univ. Press, Kassel, 2013

29. F.-W. Bach and K. Kerber, Ed., Prozesskette Präzisionsschmieden, Berlin, Heidelberg, Springer Vieweg, 2014

30. K.H. Kloos and B. Scholtes, Scholtes. Eigenspannungen in mechanisch randschichtverformten Werkstoffzuständen - Ursachen, Ermittlung und Bewertung. DGM Informationsgesellschaft mbH, Oberursel 1991, 367 Seiten, zahlreiche Abb. u. Tabellen, Mat.-wiss. u. Werkstofftech, 1991, 22(12), p 444. https://doi.org/10.1002/mawe.19910221203

31. E. Macherauch, H. Wohlfahrt, and U. Wolfstieg, Zur zweckmäßigen Definition von Eigenspannungen, HTM, 1973, 28(3), p 201-211
32. M. Ermrich and D. Opper, XRD for the Analyst: Getting Acquainted with the Principles, 2nd ed., PANalytical, Almelo, 2013

33. P. Scardi, M. Leoni, and R. Delhez, Line Broadening Analysis Using Integral Breadth Methods: A Critical Review, J. Appl. Crystallogr., 2004, 37(3), p 381-390. https://doi.org/10.1107/s0021889804004583

34. Z.-W. Hsiao, T.-Y. Wu, D. Chen, J.-C. Kuo, and D.-Y. Lin, EBSD and Electron Channeling Study of Anomalous Slip in Oligocrystals of High Chromium Ferritic Stainless Steel, Micron, 2017, 94, p 15-25. https://d oi.org/10.1016/j.micron.2016.12.003

35. Z.-W. Hsiao, D. Chen, J.-C. Kuo, and D.-Y. Lin, Effect of Prior Deformation on Microstructural Development and Laves Phase Precipitation in High-Chromium Stainless Steel, J. Microsc., 2017, 266(1), p 35-47. https://doi.org/10.1111/jmi.12516

36. M.F. Ashby, The Deformation of Plastically Non-homogeneous Materials, Philos. Mag.: J. Theor. Exp. Appl. Phys., 2006, 21(170), p 399-424. https://doi.org/10.1080/14786437008238426

37. J. Jiang, T.B. Britton, and A.J. Wilkinson, Evolution of DISLOCATION Density Distributions in Copper During Tensile Deformation, Acta Mater., 2013, 61(19), p 7227-7239. https://doi.org/10.1016/j.acta mat.2013.08.027

38. G. Spur, Handbuch Wärmebehandeln und Beschichten, 1st ed., Carl Hanser Fachbuchverlag, s.1., 2015

39. S.I. Wright, M.M. Nowell, and D.P. Field, A Review of Strain Analysis Using Electron Backscatter Diffraction, Microsc. Microanal., 2011, 17(3), p 316-329. https://doi.org/10.1017/s1431927611000055

40. D. Liedtke, M. Hoferer, K.H. Illgner, N. Pirzl, and H. Stiele, Wärmebehandlung von Eisenwerkstoffen. 10., aktualisierte Auflage. Expert verlag, Renningen, 2017

41. Grundlagen: Struktureller Aufbau von Werkstoffen; metallische Werkstoffe; Polymerwerkstoffe; nichtmetallisch-anorganische Werkstoffe; mit 4 Tabellen. 7., neu bearb. Aufl. 2013

42. W. Weißbach, Werkstoffkunde: Strukturen, Eigenschaften, Prüfung. 17., überarb. und aktualisierte Aufl. Vieweg + Teubner, Wiesbaden, 2010

Publisher's Note Springer Nature remains neutral with regard to jurisdictional claims in published maps and institutional affiliations. 